NBER WORKING PAPER SERIES

EQUITY ISSUES AND STOCK PRICE DYNAMICS

Deborah J. Lucas

Robert L. McDonald

Working Paper No. 3169

NATIONAL BUREAU OF ECONOMIC RESEARCH

1050 Massachusetts Avenue

Cambridge, MA 02138

November 1989

We are indebted to Bruce Grundy, Ravi Jagannathan, Narayana Kocherlakota and Robert Korajczyk for many helpful discussions, and to seminar participants at USC and Northwestern University. We are especially grateful to Robert Korajczyk for his help with the data. This paper is part of NBER's research program in Financial Markets and Monetary Economics. Any opinions expressed are those of the authors not those of the National Bureau of Economic Research. 
NBER Working Paper \#3169

November 1989

\title{
EQUITY ISSUES AND STOCK PRICE DYNAMICS
}

\begin{abstract}
This paper presents an information-theoretic, infinite horizon model of the equity issue decision. The model's predictions about stock price behavior and issue timing explain most of the stylized facts in the empirical literature: (a) equity issues on average are preceded by an abnormal positive return on the stock, although there is considerable variation across firms, (b) equity issues on average are preceded by an abnormal rise in the market, and (c) the stock price drops significantly at the announcement of an issue. In this model, the price drop at issue announcement is uncorrelated with the social cost of suboptimal investment due to asymetric information; the welfare loss may be small even if the price drop is large.
\end{abstract}

Deborah J. Lucas

Finance Department

Kellogg School

Northwestern University

Evanston, IL 60208

(312) $491-8333$
Robert L. McDonald

Graduate School of Business

Northwestern University and

University of Chicago

1101 E. 58th St.

Chicago, IL 60637

(312) $702-8779$ 


\section{Introduction}

The adverse selection problem when firms issue new securities has been the focus of much recent work in corporate finance. Seasoned equity issues have received particular attention, in part because there are striking stock price patterns around the time of equity issues and considerable variation over time in the number of issues. In this paper we present a dynamic, infinite horizon model of the firm's equity issue decision under adverse selection. The model can simultaneously account for each of the following empirical observations about equity issues: ${ }^{1}$

Stock prices of issuing firms on average exhibit a large and extended positive abnormal return prior to an equity issue. A sizable fraction of firms, however, have price declines in the period preceding an issue. There is substantial variation over time in the volume of equity issues. Issues on average follow increases in the market as a whole. The stock price drops significantly upon the announcement of an equity issue. After the issue announcement, returns appear to be normal.

1 Price behavior around equity issues has been extensively documented by Asquith and Mullins (1986), Masulis and Korwar (1986), Mikkelson and Partch (1986), Barclay and Litzenberger (1988), and Korajczyk, Lucas and McDonald (1989). A stylized quantitative summary of the results of these studies is as follows: researchers find an abnormal return on the order of 30 percent in the 500 days preceding the issue, but with substantial variation in the price history across firms. Equity issues appear to follow market rises. There is a significant price drop at issue announcement of about 38 for industrial issues. Asquith and Mullins (1986) find that on average, the drop in the value of a firm's total equity at issue announcement represents approximately $30 \mathrm{z}$ of the value of the equity being issued. Similar price behavior is observed for pure secondary issues.

The timing of equity issues is the focus of papers by Korajczyk, Lucas and McDonald (1988) and Choe, Masulis and Nanda (1989). The latter find that there are significantly more industrial equity issues in business cycle expansions than in contractions. 
There are of course other explanations, not based on adverse selection, for each of these facts. However, the ability of the model to explain all these phenomena in a unified framework adds support to the contention that adverse selection is of major importance in understanding equity issues. The model also sheds 1 ight on the relation between stock price behavior and the welfare consequences of adverse selection.

The price drop at issue announcement has received theoretical as well as empirical attention, ${ }^{2}$ as has the temporal variation in the volume of issues. ${ }^{3}$ The preceding price rise has not been formally modelled, however. Technically, the model differs considerably from earlier models of equity issues due to the assumptions of infinitely-lived firms and short-term information asymmetries between managers and outside investors. This allows both the long-term price path and the timing of issues to be characterized. The idea behind the model is as follows. Suppose that managers have information about the firm today (such as the value of current earnings) that the market will not acquire until next period. The firm is "undervalued" if the revelation of this information will cause the share price to rise, and "overvalued" if revelation will cause the price to drop. Suppose further that

2 Scholes (1972) suggested that informational considerations could explain the price drop. In an influential paper, Myers and Majluf (1984) presented a formal model of the price drop based on asymmetric information.

3 Korajczyk, Lucas and McDonald (1988), and Choe, Masulis, and Nanda (1989), have proposed theoretical explanations for the clustering of equity issues in certain periods. Both papers emphasize that if firms can decide when to issue equity, they will do so in periods when asymmetric information is expected to be relatively unimportant. In this paper, by contrast, bunching occurs even though the fundamental firm-level asymmetry between firms and the market is stationary through time.

Gale (1987) studies the timing of equity sales by risk-averse entrepreneurs. Delay is costly to the entrepreneur since his portfolio is undiversified. Hence, better firms can signal their quality and raise the offering price by delaying the sale. 
managers act in the interest of shareholders, and that equity issues are necessary to finance projects. If projects are long-lived and if waiting is not too costly, we would expect undervalued firms to delay issuing until the undervaluation is corrected. On the other hand, overvalued firms issue immediately, since waiting may entail the loss of the project and a downward assessment in the valuation of the firm.

This timing behavior by the two types of firm has a clear implication for the price path preceding the announcement of the equity issue. Suppose that project arrival is independent of a firm's price history. Overvalued firms will have average performance prior to their equity issue announcements since they issue immediately upon receiving a project. Undervalued firms will have above average performance preceding the equity issue, however, since they have waited for the undervaluation to vanish before issuing. Given these two prlce paths, equity issuers on average have positive abnormal returns preceding the issue.

Since firms announcing equity issues tend to be overvalued according to this explanation, the price may drop at issue announcement. ${ }^{4}$ This is a consequence of adverse selection on the part of issuing firms, as in Myers and Majluf (1984).

This story also explains variation over time in the volume of equity issues, and the fact that equity issues tend to follow general increases in the market. Suppose that the percentage of firms in the economy which are overvalued or undervalued varies randomly over time, and consider a period in which an above average number of firms have private information that they are

${ }^{4}$ If there is a cost to issuing equity, it is possible for the price to rise at the announcement of the issue. See Section 4 below. 
undervalued. As information about these firms becomes public, there will be a general market rise. An above average number of firms issue equity following the market rise because firms which anticipated an increase in their price waited to issue equity. Thus we expect to see bunching of equity issues following a general market rise.

In this paper we focus on the pricing and timing of equity issues rather than the debt-equity choice, so for simplicity we assume that the firm must use equity financing. Obviously, a complete model of the firm would also account for the choice of security. Debt can be costly for a variety of reasons including bankruptcy costs, restrictive covenants on existing debt, or the inability to use interest deductions. Thus, we think of the model as pertaining to firms that have already decided to issue equity as the lowest cost alternative. ${ }^{5}$

In the next three sections we present the model, define an equilibrium, and study the behavior of the share price around issue announcement. ${ }^{6}$ Section 5 demonstrates that issues are concentrated after market rises if the percentage of overvalued firms varies over time. In section 6 , simulation results are compared to earlier empirical findings. For plausible parameter values, the simulations generate realistic price paths and time variation in issues. Section 7 discusses the welfare implications of the analysis. The

${ }^{5}$ Consider a world in which debt issues are free of adverse selection problems, but in which existing debt is more costly than existing equity. It seems likely that in such a model, firms would use debt for "bridge financing" but would issue equity to replace the debt when the firm became overvalued. In such an equilibrium, the predicted price dynamics and timing of issues should be qualitatively the same as in the model without debt.

6 In practice the announcement date precedes the actual issue date by several weeks, and the larger price effect is seen at the announcement. In this paper we do not distinguish the two events, so henceforth we will refer simply
to the issue date. 
conventional wisdom that the cost of an equity issue can be measured by the stock price drop at issue is incorrect in this model. We suggest a measure of the true cost. Section 8 concludes.

\section{The Environment}

This section describes the enviroment in which firms and investors operate.

\section{i. The Firm}

At time $t$ a firm's market value equals the perceived value of its assets in place $A_{t}$, and the present value of all future investment opportunities.

Each period the market receives news about the value of assets in place, which change by a constant proportion each period:

$$
A_{t+1}- \begin{cases}u A_{t} & \text { with probability } p \\ d A_{t} & \text { with probability (1-p) }\end{cases}
$$

where $u>1>d$. (Time variation in $p$ will be introduced in Section 5 below.) On average, perceived asset value remains unchanged: $u p+d(1-p)-1$. At time $t$, the manager knows next period's news, and hence knows $A_{t+1}$, the value the market will assign to assets in place next period. Thus, the manager has "one-step-ahead" knowledge of $\mathrm{A}_{t} \cdot 7$

Valuable investment opportunities which we call "projects" arrive with constant probability $q$, independently of whether the value of assets in place increases or decreases. A firm receives at most one project per period. If a firm with a project receives a second project, the second displaces the first

7 Evidence that management can successfully anticipate market price is given by Seyhun (1986), who shows that insiders systematically earn positive abnormal returns on purchases and sales of their stock. 
so that the firm only has one viable project at a time. (This can be motivated by the assumption that the firm has a scarce resource required to maintain projects which have arrived but not been taken.) 8 We assume that a project can only be undertaken if equity is issued. The market cannot observe whether or not a firm has a project before it is financed.

With probability $1-\rho$ the firm loses all current projects and future project arrivals, and is liquidated for $A_{t} \cdot{ }^{9}$ To maintain a stationary equilibrium, we assume that a new firm with no price history replaces each firm that is liquidated. Once a project arrives, it lasts as long as the firm remains viable. 10

In order to invest in a project the firm must raise $\mathrm{KA}_{t}$ from equity issues. The net value of the project (gross of issue costs) is $\beta_{\mathrm{H}^{\mathrm{A}} \mathrm{t}+\mathrm{I}}$. Thus, the capital requirement for the project is linked to a publicly known quantity, but the value is linked to next period's asset value and thus is privately known by the manager. The proportionality assumption is made for tractability; similar results will obtain if, for example, $\mathrm{K}$ and $\beta_{\mathrm{H}}$ are fixed. 11

8 We restrict the number of projects simultaneously available primarily to avoid the complexity of making the amount of capital raised a choice variable.

9 The possibility of Iiquidation keeps the value of the firm finite. Otherwise, a non-dividend-paying firm with no chance of liquidation and which is expected to receive an infinite stream valuable projects would have an infinite value.

10 It is possible to analyze the case in which projects live only a finite number of periods. This complicates the analysis without changing the qualitative results.

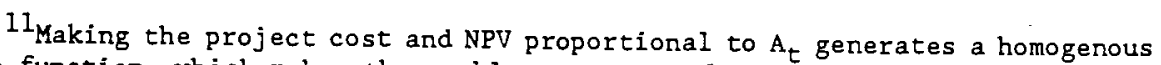
value function, which makes the problem easy to solve. If the project cost and NPV were fixed, the solution would depend upon the size of the firm relative to the project, and there would be regions in which high and low asset value firms separated, and regions in which they pooled. 
Any firm which issues equity, whether or not it has a project, bears a $\cos t \beta_{\mathrm{L}} \mathrm{A}_{\mathrm{t}+1}, \beta_{\mathrm{L}}<0$, which can be thought of as an underwriting fee and associated distribution costs. Thus, a project has a net present value proportional to $\beta_{\mathrm{H}}-\beta_{\mathrm{H}}^{*}+\beta_{\mathrm{L}}$. Henceforth, we will speak of firms as having a project with value $\beta_{\mathrm{H}^{A}} \mathrm{t}_{+1}$, or having no project, in which case the firm can issue equity at a cost $\beta_{\mathrm{L}} \mathrm{A}_{\mathrm{t}+\mathrm{l}}$.

Since investors cannot observe the arrival of profitable investment opportunities, $\beta_{\mathrm{H}}$ and $\beta_{\mathrm{L}}$ firms are ex ante indistinguishable. We assume that investors learn the true value of a project immediately after it is financed.

\section{ii. Managers}

Managers choose equity issue policy so as to maximize the value of the firm to current shareholders. As described above, managers know today what the market will learn next period about the value of assets in place. Since the act of issuing equity can lower share price, however, shareholders may disagree about the desired equity issue policy. For example, shareholders who are about to sell shares may prefer that the manager delay or forego a project if issuing equity to finance the project lowers the current stock price. 12 We assume a sufficient number of long-term shareholders so that management acts in their interest. 13

Project value is assumed to be proportional to $A_{t+1}$ so that managers have no incentive to wait to take projects in the absence of asymetric information.

12 We know of no entirely satisfactory solution to this problem. Miller and Rock (1985), and John and Williams (1985) discuss this issue in the context of dividend and investment policy.

13 For instance, suppose that shareholders are voting on a permanent shareissuance policy. Every shareholder knows that at some time they will be a shortterm shareholder, and at that time would vote for the manager to forego share issuance. But it will generally still be in their interest to vote in favor of 
Our results (and those of Myers and Majluf (1984), for example) depend on the assumption that managers cannot write a contract allowing them to credibly reveal their private information (Dybvig and Zender (1988)). If managers could do so, issuing equity would be costless and all projects would be financed immediately. Although such a contract is easy to envision in this stylized model, there are difficulties with implementing such a contract in practice. First, it may be hard to prove exactly when a manager acquires information. Second, it may be hard to prove that the manager knew how the market would interpret the information. Third, the manager may have quit or retired by the time the information is revealed. Considerations such as these suggest that contracts can reduce but not eliminate problems of asymmetric information.

\section{iii. Investors}

Investors are competitive and risk-neutral. In buying newly-issued equity, they acquire a share of the firm, $s$, in exchange for providing $K A_{t}$. Investors have access to other investments with a zero expected rate of return.

We summarize the assumed timing of events and information within a period in Figure 1.

taking projects, since never taking a project permanently lowers the value of the firm. 


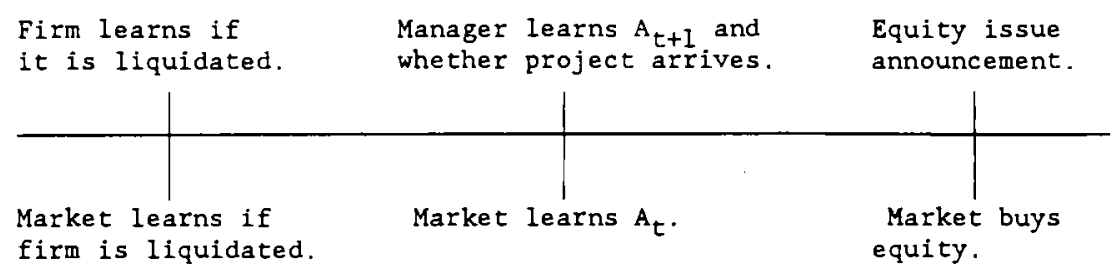

Figure 1: The resolution of uncertainty at time $t$.

\section{Equilibrium}

In any period, firms are assumed to follow a pure strategy of issuing or not issuing equity, and are price-taking with respect to the terms of a sale. We define an equilibrium as follows:

Definition. An equilibrium in the equity issue market is a share $s$ and an issue policy by firms such that

i. Investors weakly prefer to pay $\mathrm{KA}_{t}$ for a share $s$ of an issuing firm than to invest in an alternative.

ii. Firms weakly prefer this issue policy to any other, taking $s$ as given. The share s may be a function of the commonly observed price history, and the issue policy may be a function of the manager's information.

In this section we posit a time-invariant issue policy and derive sufficient conditions for it to be an equilibrium. Existence is demonstrated by numerical example in section 6 . 
i. The Value of the Firm From the Manager's Perspective

The manager has private knowledge at time that the perceived value of assets in place will increase (to $u A_{t}$ ) or decrease (to $d A_{t}$ ), and that the firm either has or does not have a project. Thus there are four basic types of firms.

Since equity issues will be more costly for undervalued firms than for overvalued firms due to dilution, it is plausible that undervalued firms will defer taking projects, even though they face the prospect that the firm may be liquidated before the project can be taken. If overvalued firms do not take projects, no firm will do so. With this as the intuitive rationale, we will examine an equilibrium with the following properties:

(E1) undervalued firms forego issuing equity even if they have a good project,

(E2) all overvalued firms with a good project issue,

(E3) overvalued firms without a good project do not issue, and

(E4) investors receive a fraction of the firm $s$ such that the expected value of their shares is equal to the amount invested, $\mathrm{KA}_{t}$.

Let $V(a, b) A_{t}$ be the manager's valuation of the firm following the proposed policy $(E I)-(E 3)$ at time $t$ in state $(a, b)$, where $a=u, d$ and $b=\beta_{L}, \beta_{\mathrm{H}}$. This valuation includes the share of the expected value of future new projects accruing to existing shareholders, as well as the value of assets in place. Because the value of assets in place, project value, equity issue costs, and necessary capital are all proportional to $A_{t}$, the manager's valuation will also be proportional to $A_{t}$. (E1)-(E4) imply that the value of the firm, 
$V(a, b)$, must satisfy the following set of equations (Appendix A contains a more formal treatment of the maximization problem):

$$
\begin{aligned}
& \text { (1) } \quad \mathrm{V}\left(\mathrm{u}, \beta_{\mathrm{L}}\right)=(1-\rho) \mathrm{u}+\rho(1-\mathrm{q}) \mathrm{u}\left[\mathrm{pV}\left(\mathrm{u}, \beta_{\mathrm{L}}\right)+(1-\mathrm{p}) \mathrm{V}\left(\mathrm{d}, \beta_{\mathrm{L}}\right)\right]+ \\
& \rho \mathrm{qu}\left[\mathrm{pV}\left(\mathrm{u}, \beta_{\mathrm{H}}\right)+(1-\mathrm{p}) \mathrm{V}\left(\mathrm{d}, \beta_{\mathrm{H}}\right)\right] \\
& \text { (2) } \quad \mathrm{V}\left(\mathrm{u}, \beta_{\mathrm{H}}\right)-(1-\rho) \mathrm{u}+\rho \mathrm{u}\left[\mathrm{pV}\left(\mathrm{u}, \beta_{\mathrm{H}}\right)+(1-\mathrm{p}) \mathrm{V}\left(\mathrm{d}, \beta_{\mathrm{H}}\right)\right] \\
& \text { (3) } \mathrm{V}\left(\mathrm{d}, \beta_{\mathrm{L}}\right)=(1-\rho) \mathrm{d}+\rho(1-\mathrm{q}) \mathrm{d}\left[\mathrm{pV}\left(\mathrm{u}, \beta_{\mathrm{L}}\right)+(1-\mathrm{p}) \mathrm{V}\left(\mathrm{d}, \beta_{\mathrm{L}}\right)\right] \\
&+\rho \mathrm{qd}\left[\mathrm{pV}\left(\mathrm{u}, \beta_{\mathrm{H}}\right)+(1-\mathrm{p}) \mathrm{V}\left(\mathrm{d}, \beta_{\mathrm{H}}\right)\right] \\
&=\mathrm{dV}\left(\mathrm{u}, \beta_{\mathrm{L}}\right) / \mathrm{u} \\
& \text { (4) } \mathrm{V}\left(\mathrm{d}, \beta_{\mathrm{H}}\right)=(1-\mathrm{s})\left[\mathrm{d} \beta_{\mathrm{H}}+\mathrm{K}+\mathrm{V}\left(\mathrm{d}, \beta_{\mathrm{L}}\right)\right]
\end{aligned}
$$

Equations (1)-(4) define the value of the firm to existing stockholders, conditional upon the manager's information, under the proposed equilibrium issue policy. Equation ( 1$)$ is the value of a firm in state $\left(u, \beta_{L}\right)$ that does not issue. With probability $(1-\rho)$ the firm matures the following period and is liquidated with a terminal payment of $u$. Otherwise it begins the next period with assets perceived to be worth $u$ times asset value this period, and with the appropriate probability falls into one of the four states (i.e. the manager will learn that the news two periods hence is $u$ or $d$, and whether a project has arrived). Equation (2) reflects the fact that an undervalued firm postpones or forgoes the project entirely to avoid dilution by pooling with overvalued firms. Equation (3) demonstrates the symmetry between the two types of firms without projects. Finally, (4) indicates that a firm in state $\left(d, \beta_{\mathrm{H}}\right)$ benefits from investment in the project, but loses a fraction $s$ of its value to new shareholders. 
Equations (1)-(4) treat $s$ as given. The share $s$ is determined by imposing condition (E4) that investors receive a fair value for new shares purchased. Since only overvalued firms with good projects issue in the proposed equilibrium, ${ }^{14} \mathrm{~s}$ is defined by:

$$
\mathrm{K}=\mathrm{s}\left(\mathrm{K}+\mathrm{d} \beta_{\mathrm{H}}+\mathrm{V}\left(\mathrm{d}, \beta_{\mathrm{H}}\right)\right) \text {. }
$$

Substituting this into (4) gives:

$$
\mathrm{v}\left(\mathrm{d}, \beta_{\mathrm{H}}\right)=\mathrm{d} \beta_{\mathrm{H}}+\mathrm{v}\left(\mathrm{d}, \beta_{\mathrm{L}}\right)
$$

Note that the system (1), (2), (3) and $\left(4^{\prime}\right)$ is linear in $v$. The unique solution is given in Appendix A.

\section{ii. Sufficlent Conditions for Equilibrium}

To establish that the proposed policy is an equilibrium, we must ask whether a firm in any given state would do better deviating from the proposed policy, holding the share $s$ fixed. The number of potential policy variations is infinite, since a firm can plan to deviate once or multiple times and in any combination of states. It can be shown, however, that if a one period deviation decreases firm value in each state individually, so does an arbitrary multi-period deviation. This result is formalized in Theorem I,

${ }^{14}$ If $\beta_{\mathrm{L}}$ is not sufficiently negative, then some firms with low asset value may choose to issue equity in order to pool with better firms. It is possible to impose a weaker restriction on $\beta_{L}$ so that overvalued firms without a project played a mixed strategy between issuing and not issuing. This results in similar price dynamics, but more complicated algebra.

Note that the fair share $s$ under (E1)-(E4) is history-independent because the issue policy is history-independent. 
which is stated and proved in Appendix A. Thus, verifying that a proposed strategy is an equilibrium only requires checking that a one-time deviation by a firm in each of the four basic states lowers firm value. The investor's optimization problem clearly is satisfied by the imposition of (E4).

The policy proposed in (El)-(E4) will not be an equilibrium for arbitrary parameter values. Intuitively, the willingness of undervalued firms to postpone financing a project increases with the degree of information asymetry (the difference between $d$ and $u$ ), and increases with project and firm durability. If the information asymetry is small, then in equilibrium all firms with projects issue immediately. Also if $\left|\beta_{L}\right|$ is sufficiently small, firms with low quality assets and no project may prefer to issue equity to pool with higher quality firms. The numerical examples presented later illustrate that the proposed equilibrium obtains with plausible parameter values. This equilibrium will be assumed in the analysis of pricing and timing below.

Multiple equilibria may exist for a given set of parameter values. This occurs when the willingness of a firm to issue depends on whether it believes other firms of the same type are also issuing. For example, if $\left(u, \beta_{H}\right)$ firms issue as well as $\left(\mathrm{d}, \beta_{\mathrm{H}}\right)$ firms, the equilibrium share $s$ is lower than if only $\left(d, \beta_{H}\right)$ firms issue because the former are more valuable to investors. Thus there may be two equilibria: one with a low $s$ and both types issuing, and one with a high s and only $\left(\mathrm{d}, \beta_{\mathrm{H}}\right)$ firms issuing. Standard refinements of Nash equilibria cannot eliminate this type of multiplicity. 


\section{Share Price Behavior}

\section{i. The Market Price of a Share}

Thus far we have concentrated on the manager's valuation of the firm. Investors, however, can only use publicly available information in computing price. Investors know the distribution of firm types in equilibrium, so the market valuation for a firm will be a weighted average of the values of the various types of firms. Interestingly, price is history-dependent because the probability that a firm has an unexploited project increases in the number of periods since the last fall in asset value.

Let $q_{i}$ denote the probability that a firm with exactly $i$ consecutive asset value increases has a project. Recall that the last time management foresaw an asset value decrease, they adopted any available project. If the firm has experienced exactly $n$ asset value increases since that time, the probability of having a project is one minus the probability of not having received a project since the initial drop in asset value:

$$
q_{n}=1-(1-q)^{n+1} \quad n=0,1,2, \ldots
$$

Let $P(n) A_{t}$ be the time $t$ stock price immediately prior to announcement of an issue, where $n$ is the number of consecutive price rises for the firm. The price is separable in $A_{t}$ because the value function is separable. With probability $q_{n}$ the firm has a project, and with probability $p$ the management privately observes a rise in asset value. Taking these possibilities into account we have:

$$
\begin{aligned}
& \mathrm{P}(\mathrm{n})=\mathrm{p}\left[\mathrm{q}_{\mathrm{n}} \mathrm{V}\left(\mathrm{u}, \beta_{\mathrm{H}}\right)+\left(1-\mathrm{q}_{\mathrm{n}}\right) \mathrm{V}\left(\mathrm{u}, \beta_{\mathrm{L}}\right)\right] \\
& \quad+(1-\mathrm{p})\left[\mathrm{q}_{\mathrm{n}} \mathrm{V}\left(\mathrm{d}, \beta_{\mathrm{H}}\right)+\left(1-\mathrm{q}_{\mathrm{n}}\right) \mathrm{V}\left(\mathrm{d}, \beta_{\mathrm{L}}\right)\right] \quad \mathrm{n}=0,1,2, \ldots
\end{aligned}
$$


From equation (7) it is clear that the market price for a firm is increasing in the number of consecutive rises in asset value, as shown in the following lemma:

Lemma 1. In an equilibrium characterized by (E1)-(E4), P(i) is increasing in i.

Proof: Lemma $\mathrm{A} 3$ in Appendix $\mathrm{A}$ shows that $\mathrm{V}\left(\cdot, \beta_{\mathrm{H}}\right)>\mathrm{V}\left(\cdot, \beta_{\mathrm{L}}\right)$. Further, $\mathrm{q}_{\mathrm{n}}$ is increasing in $\mathrm{n}$. Consequently, the result follows from $(7) \cdot / /$

\section{ii. Price Behavior At Issue}

To measure the short-term effect on stock prices of an equity issue, we compare the market price immediately before and after issue. Equation ( $4^{\prime}$ ) provides the price after issue, with $A_{t}$ normalized to 1 . Subtracting equation (7) gives the price drop for a firm with $n$ consecutive asset value increases:

$$
\begin{aligned}
& \mathrm{d} \beta_{\mathrm{H}}+ \mathrm{V}\left(\mathrm{d}, \beta_{\mathrm{L}}\right)-\left(\mathrm{p}\left(\mathrm{V}\left(\mathrm{u}, \beta_{\mathrm{H}}\right)+(1-\mathrm{q})^{\mathrm{n}+1}\left[\mathrm{~V}\left(\mathrm{u}, \beta_{\mathrm{L}}\right)-\mathrm{V}\left(\mathrm{u}, \beta_{\mathrm{H}}\right)\right]\right)\right. \\
&+(1-\mathrm{p})\left(\mathrm{V}\left(\mathrm{d}, \beta_{\mathrm{H}}\right)+(1-\mathrm{q})^{\mathrm{n}+1}\left[\mathrm{~V}\left(\mathrm{~d}, \beta_{\mathrm{L}}\right)-\mathrm{V}\left(\mathrm{d}, \beta_{\mathrm{H}}\right)\right]\right)
\end{aligned}
$$

The sign of this expression depends on the degree of information asymmetry, and on the number of consecutive asset value increases. As $n \rightarrow \infty$, this becomes $\mathrm{P}\left[\mathrm{V}\left(\mathrm{d}, \beta_{\mathrm{H}}\right)-\mathrm{V}\left(u, \beta_{\mathrm{H}}\right)\right]$, which is negative. The logic is that a firm with a large number of asset value increases is almost sure to have a project, so the decision to issue equity reveals only that the value of assets in place will fall. For other firms, the decision to issue equity reveals 
both a negative return on assets in place and the existence of a project, so the price effect can be ambiguous. 15

iii. The Equilibrlum Price Path Prlor to Issue

This section discusses our main result:

Theorem 2: In the equilibrium described by (E1)-(E4), the average excess returns for a firm issuing equity are positive over the $n$ periods preceding the issue, where $n$ is any positive integer.

The proof of Theorem 2 is in Appendix B. Here we discuss the logic and robustness of the result.

The idea of the proof is simple. We compute the average return earned over $n$ periods by all firms, ${ }^{16}$ and compare this to the average return earned over n periods by all firms which issue equity in the nth period. The average return for firms which issue equity exceeds the unconditional return because firms which have had price rises accumulate projects and are therefore overrepresented (relative to all firms) in the sample of firms issuing equity.

Because projects last as long as the firm does, the duration of the price rise is unbounded. However, the incremental price rise from looking

15 Myers and Majluf (1984) note that if equity issues are costly, the announcement of an equity issue can raise the stock price. The costly equity issue serves as a credible signal about the value of the project.

${ }^{16}$ One might expect a zero average return across all firms, which is the case unconditionally. In this calculation, however, there is a survivorship bias: the selection of firms that were not liquidated in the last $n$ periods induces a positive unconditional return. 
back over a longer horizon goes to zero as $\mathrm{n}$ becomes large, because the probability that a project was postponed for $n$ periods becomes small. 17

This qualitative pattern of price behavior clearly depends upon the assumed equilibrium. If $u$ and $d$ are close together, for example, so that all firms issue equity upon receipt of a project, the returns earned by issuing firms are the same as the returns for all firms. Thus, the model predicts that firms with different degrees of asymetric information should have different price behavior both preceding and immediately following the issue announcement. 18

Finally, the model implies that firms that have had a larger price rise prior to the issue will face a larger price drop at announcement of the issue. This occurs because firms with a longer string of price rises on average have a higher probability of having a project and thus have a higher pre-issue price. After the project is taken, all firms have the same price. 19 Empirical evidence on the relation between the price rise and the drop is mixed. 20

One possible alternative to this reason for the price rise is that the market learns about the arrival of a valuable project, the stock price rises

17 It can be shown that if project life is finite, then the price rise will last no longer than the maximum life of a project.

18 For instance, asymetric information may be less of a problem for public utilities because they have regulated rates of return. In fact, utilities appear to depend more on equity issues than other industries, and Masulis and Korwar (1986) find evidence that the price drop for utilities is smaller.

19 Unlike the price rise, this result does not appear to be robust with respect to model specification.

20 Korajczyk, Lucas, and McDonald (1989) show that the price drop is negatively correlated with the price rise over long periods and positively correlated over short periods, a result consistent with apparently contradictory results in Asquith and Mullins (1986) and Masulis and Korwar (1986). 
in response to this information, and the firm subsequently issues stock to finance the project. 21 This story, however, leaves unexplained the price drop at issue announcement, and also does not account for the price rise preceding pure secondary issues, in which the firm raises no funds and which therefore are not necessarily linked with project arrival. 22

\section{The Relation Between the Number of Equity Issues and the Return on the}

\section{Market}

In the analysis thus far, the return on the market was assumed to be the same every period. As discussed above, equity issues are not uniform over time; they tend to follow a general rise in the market. A simple modification of the model generates time variation in the number of issues, and permits us to analyze the relation between equity issues and the return on the market.

First we calculate the quantity of equity issues in any period when the probability of an increase in asset value is constant. This requires counting the number of issues by firms with different price histories. The unconditional probability of having $n$ consecutive price rises and surviving $n$ periods is $(\rho \mathrm{P})^{n}$, for $n=1,2, \ldots$. Since probabilities add to one, the fraction of firms with a price drop or no price history (i.e., new firms) is $(1-\rho p)$. Thus the probability of having exactly $n$ consecutive price increases is $(\rho p)^{n}(1-\rho p)$. For a firm to issue in the current period, it must have a project (which it does with probability $q_{n}$ ), and the manager must observe a

21 The price rise in our model is not consistent with this story since project arrival is assumed to be unobservable.

${ }^{22}$ Price behavior preceding secondary issues is qualitatively similar to that for primary issues. For a more complete discussion of alternative theories, see Korajczyk, Lucas, and McDonald (1989). 
drop in asset value (which occurs with probability (1-p)). The quantity of issues at any time is therefore:

$$
\left.(1-p) \sum_{i=0}^{\infty} q_{i}(1-p \rho)(p \rho)^{i}=(1-p) q / i 1-\rho p(1-q)\right]
$$

Note that the number of issues in (9) is less than $q$, the number that would obtain in the absence of asymmetric information.

To capture the fact that aggregate returns fluctuate and that returns are correlated across firms, we now suppose that the probability of an increase in the perceived asset value between times $t$ and $t+1$ for each firm is stochastic:

$$
p_{t}=p+\epsilon_{t}
$$

$\epsilon_{t}$ has mean zero, support $(-p, 1-p)$, and is Independently and identically distributed over time. Neither the market nor managers observe $\epsilon_{t}$ until time $t+1$, so at $t$ the expected probability of an increase is p. Equations (1) $-\left(4^{\prime}\right)$ are linear in $p$, hence they remain unchanged when the probability of an increase in asset value is given by $(10)$, and when $\epsilon_{t}$ is independent of project arrivals. If $p_{t}$ exceeds $p$, the aggregate return will be greater than average. Thus we can think of a "market rise" as occurring when $p_{t}$ exceeds $p$ several times in a row.

More precisely, the unconditional market price at time $t$ reflects historical probabilities, the realized values of assets in place, and the relative proportions of firms with different price histories. Let $\overline{\mathrm{A}}_{t}$ denote the average aggregate value of assets in place at time $t$. Then the unconditional market price at time $t$ is: 


$$
\begin{aligned}
& M_{t}=\bar{A}_{t}\left(\sum_{i=0}^{\infty} P(i)\left(1-\rho P_{t-i-1}\right) \prod_{k=1}^{i} \rho P_{t-k}\right. \\
& \text { where } \bar{A}_{t}=\bar{A}_{t-1}\left[u P_{t-1}+d\left(1-P_{t-1}\right)\right]
\end{aligned}
$$

Market returns can be calculated by simply taking ratios of the market price at different points in time.

The quantity of issues at time $t$ is given by equation (9), modified to keep track of the historical fraction of firms with an increase in asset value:

$$
\left(1-p_{t}\right) \sum_{i=0}^{\infty} q_{i}\left(1-\rho p_{t-i-1}\right) \underset{k=1}{i} \rho p_{t-k}
$$

Appendix $C$ establishes that (11) and (12) increase in $p_{t-k}$ for $k>0$. Thus, following a number of greater than average $P^{\prime} s$, there tends to be a greater than average number of issues as well as a general rise in the market. 23 We explore the magnitude of this correlation by simulation in the next section.

\section{Simulations}

This section compares model simulation results with corresponding empirical results from Korajczyk, Lucas, and McDonald (1989). 24 with

23 Note that the informational asymmetry between managers and outside investors is constant over time, as is the value of a project relative to assets in place. These assumptions rule out the explanations for equity issue timing offered by Choe, Masulis, and Nanda (1989) and Korajczyk, Lucas, and McDonald (1988), which are based on time-varying asymetry.

${ }^{24}$ The sample contains 549 seasoned equity issues by NYSE/AMEX industrial firms over the period 1974 to 1983. The abnormal return for each stock was computed relative to an equal-weighted portfolio of NYSE/AMEX and OTC stocks, without adjusting for individual firm betas. Stock and index returns are from the Center for Research in Securities Prices tape. The price drop at announcement of the issue was measured over a two-day window including the day before the announcement. Equity issues were obtained from Drexel Burnham, Lambert's Public Offerings of Corporate Securities (various years), and 
reasonable parameter values, we find that the model reproduces most of the stylized facts discussed in the introduction.

All the simulations employ the parameters listed in Table 1 . The existence of an equilibrium for these values was verified following Theorem 1 . Parameters were chosen to calibrate the model to some general features of the data, and to match the empirical distributions. In fact, a large range of parameter values admit qualitatively similar results. ${ }^{25}$ The values of $p, d$, and $u$ imply a quarterly standard deviation of $20 z$, or an annual standard deviation of $40 z$. The distribution of $\epsilon_{t}$ leads to a 28 annual, or 148 quarterly, standard deviation of aggregate market returns. ${ }^{26}$

Table I. Simulation Parameters

$\begin{array}{llcc}\rho=.99 & \beta_{\mathrm{H}}=0.3 & \mathrm{p}-0.5 & \mathrm{u}=1.2 \\ \mathrm{~K}=.2 & \beta_{\mathrm{L}}=-0.05 & \mathrm{q}=.009 & \mathrm{~d}-0.8\end{array} \epsilon_{\mathrm{t}}-\left\{\begin{array}{cc}.35 & \mathrm{pr}=.5 \\ -.35 & \mathrm{pr}-.5\end{array}\right\}$

Figure 2 illustrates the simulated average excess returns conditional on issuing over the eight quarters prior to issue, and the price drop at issue. The cumulative abnormal return over the entire period is 24.48 , with a drop at issue of 2.88 . This is quite similar to Figure 3 , which has a 47 rise and a

announcement dates from the Wall Street Journal Index. The data and calculations are described in detail in Korajczyk, Lucas, and McDonald (1989).

25 All simulations were done in GAUSS. The programs are available upon request.

${ }^{26}$ The total return in a period is $(p+\epsilon) u+(1-p-\epsilon) d-\epsilon(u-d)$. For the parameters in Table $1, \epsilon(u-d)=.14$. Since $\epsilon$ is binomially distributed, .14 is the quarterly standard deviation. 
38 drop at issue, and which was constructed using market data on issuing firms. 27

The model generates a cross-sectional distribution of price histories for issuing firms as well as the average price rise. The possibility of negative returns prior to an issue arises because some firms which issue will have suffered a string of price decreases followed by a project arrival. The predicted distribution can be derived analytically, following the logic of equation (B1) in Appendix B. The simulated distribution based on this equation is illustrated in Figure 4. Each bar represents the percentage of firms with pre-issue cumulative abnormal returns less than or equal to the number on the $x$-axis, and greater than the previous number on the $x$-axis. By comparison, Figure 5 shows the empirical distribution of returns in the seven quarte:s preceding an actual issue. The predicted percentage of firms with a loss in the two years preceeding the equity issue is $37 \%$, while the actual percentage is $23 \%$.

Finally, Figure 7 shows that on average, market rises precede equity issues, while Figure 6 illustrates the same relation for model-generated data. Figure 6 was generated as follows. A sequence of 1000 i.i.d. random numbers was used to create a probability sequence $\left(\mathrm{p}_{t}\right)$, as described in section 5 . The number of issues each period was calculated using (12), with the index i truncated at 15 (the approximation error is small since $p^{15}=10^{-5}$ at $p=.5$ ). The corresponding unconditional market returns history at each date was computad using (11). The price history in the eight quarters preceding each

27 Korajczyk, Lucas and McDonald (1989) find that the predicted excess return is very sensitive to how the excess return is estimated. Although all methods yield a positive excess return, estimates using different market indices range from 208 to 808 over the 500 day period. Thus, we put more emphasis on picking "plausible" parameters, rather than matching the empirical rise exactly, 


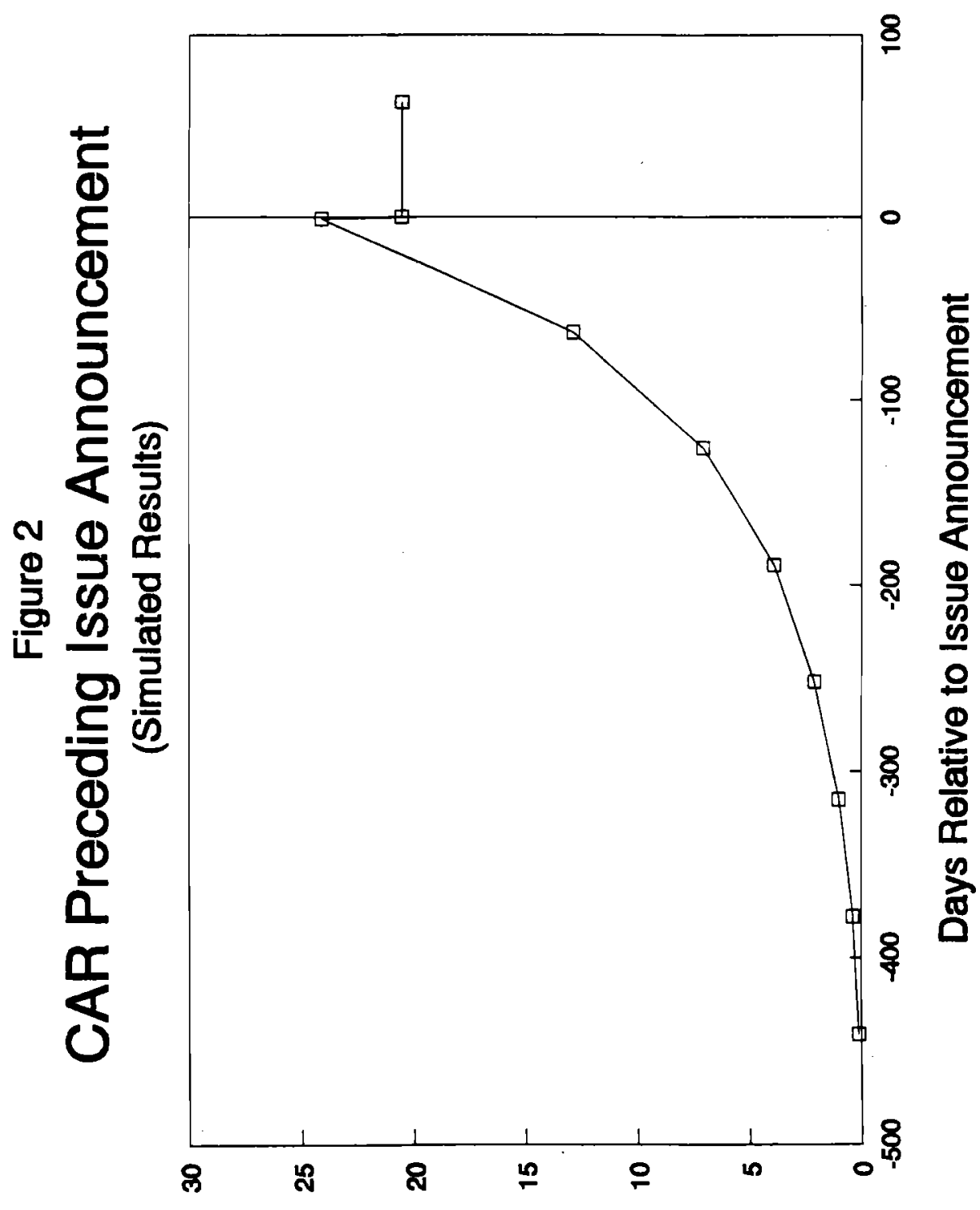

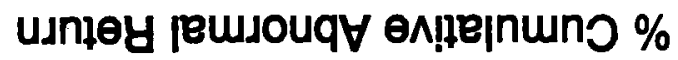




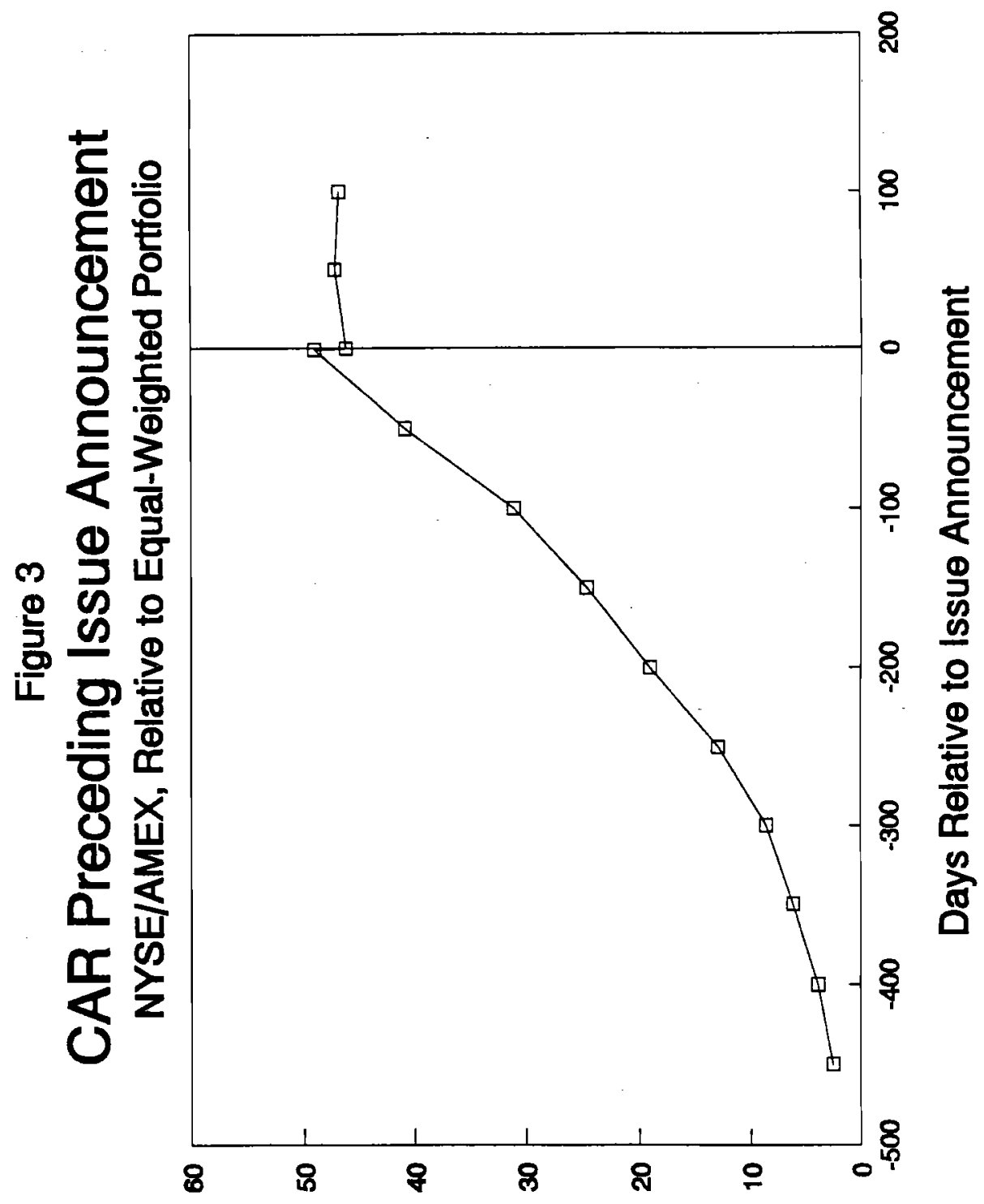

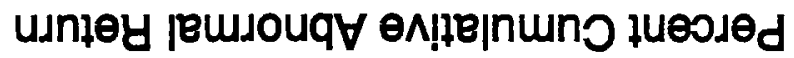




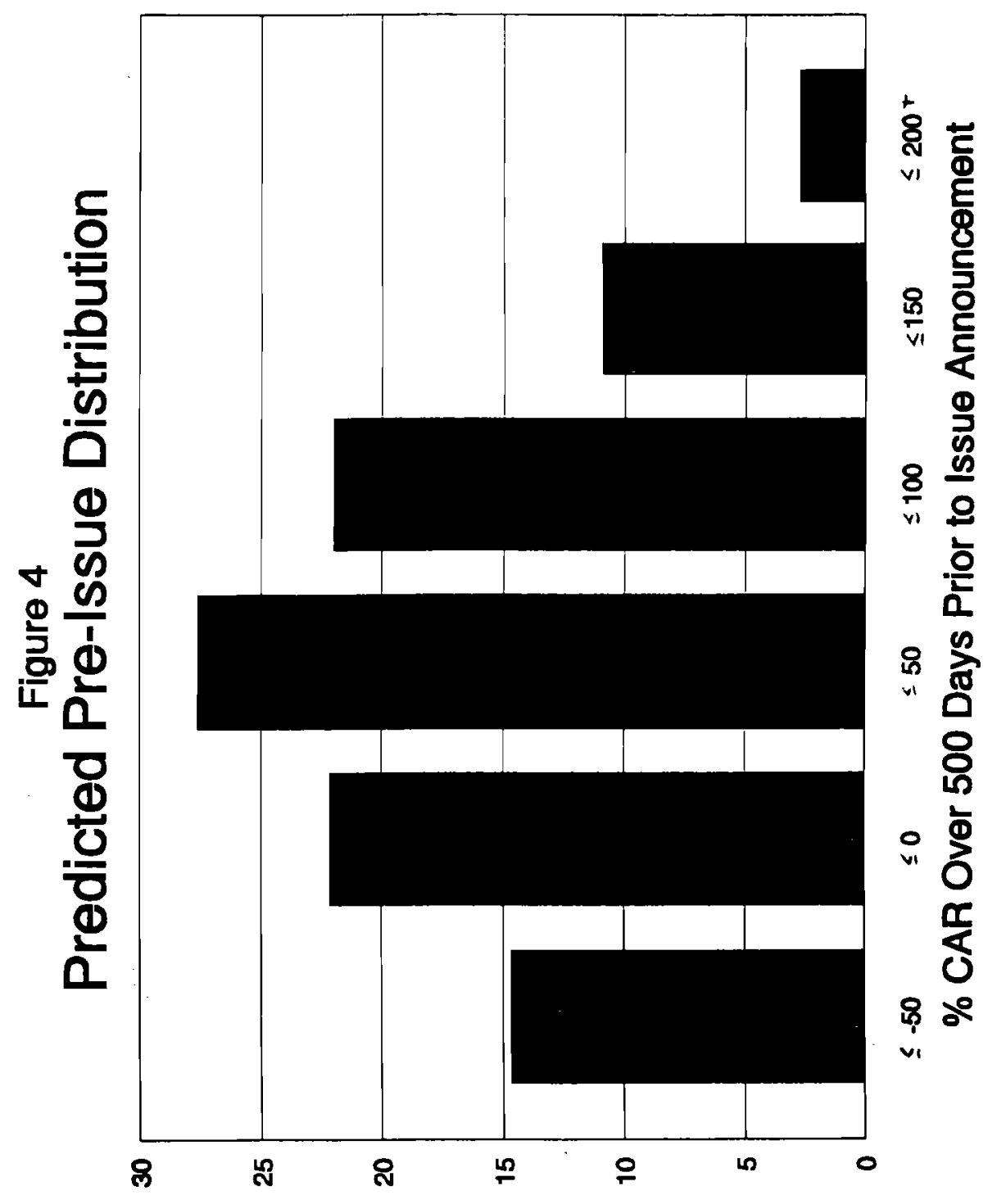

sun! J 10 luested 


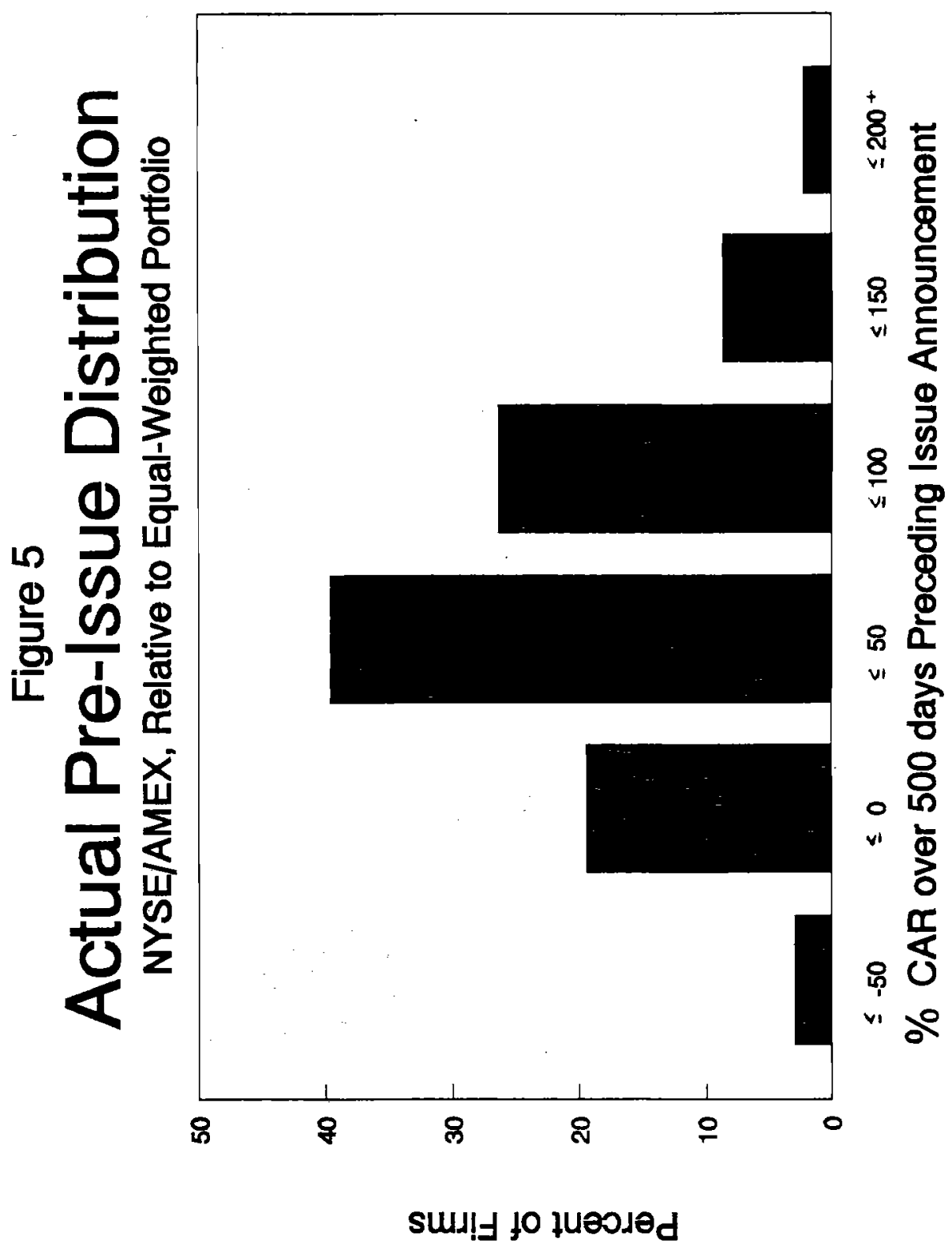




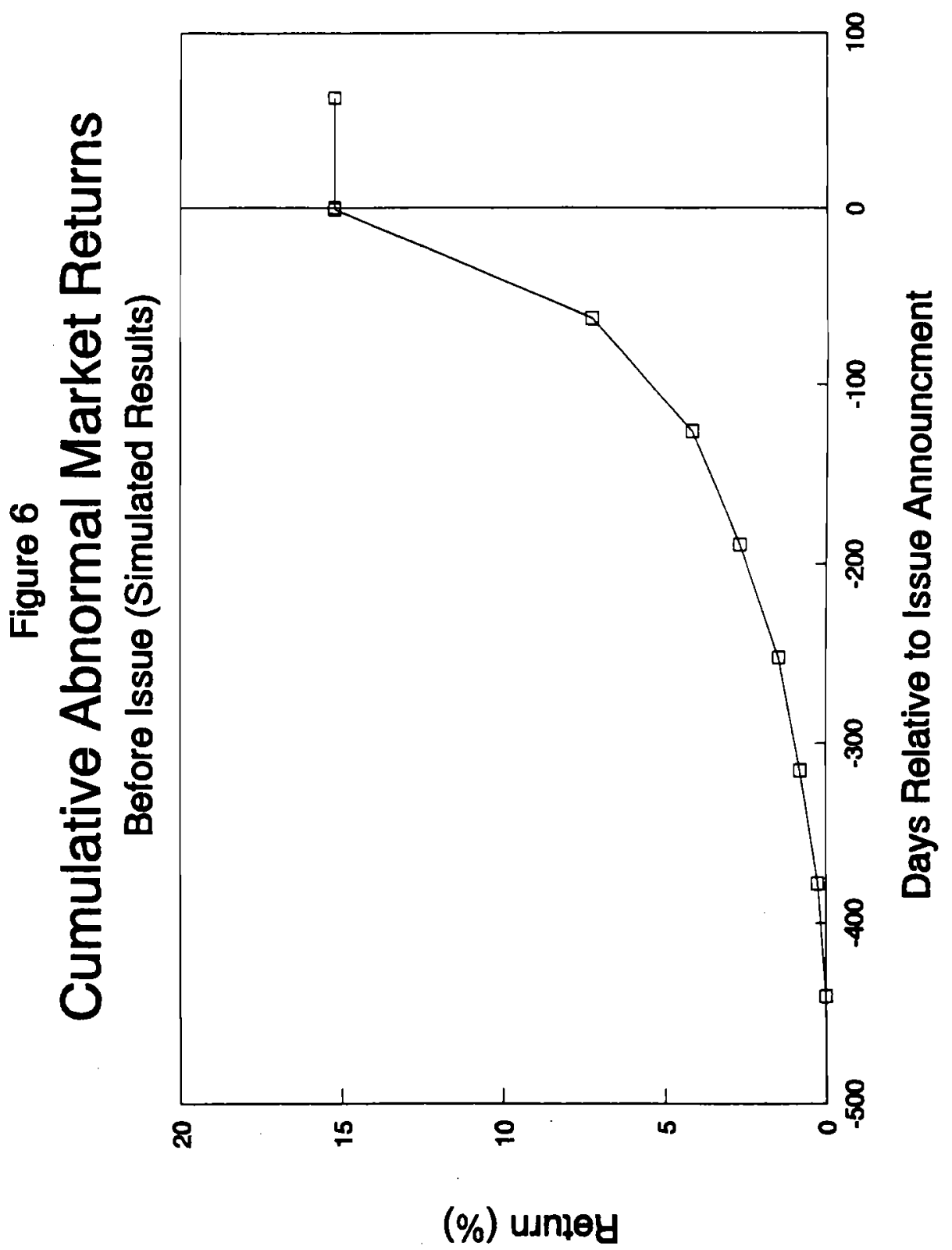




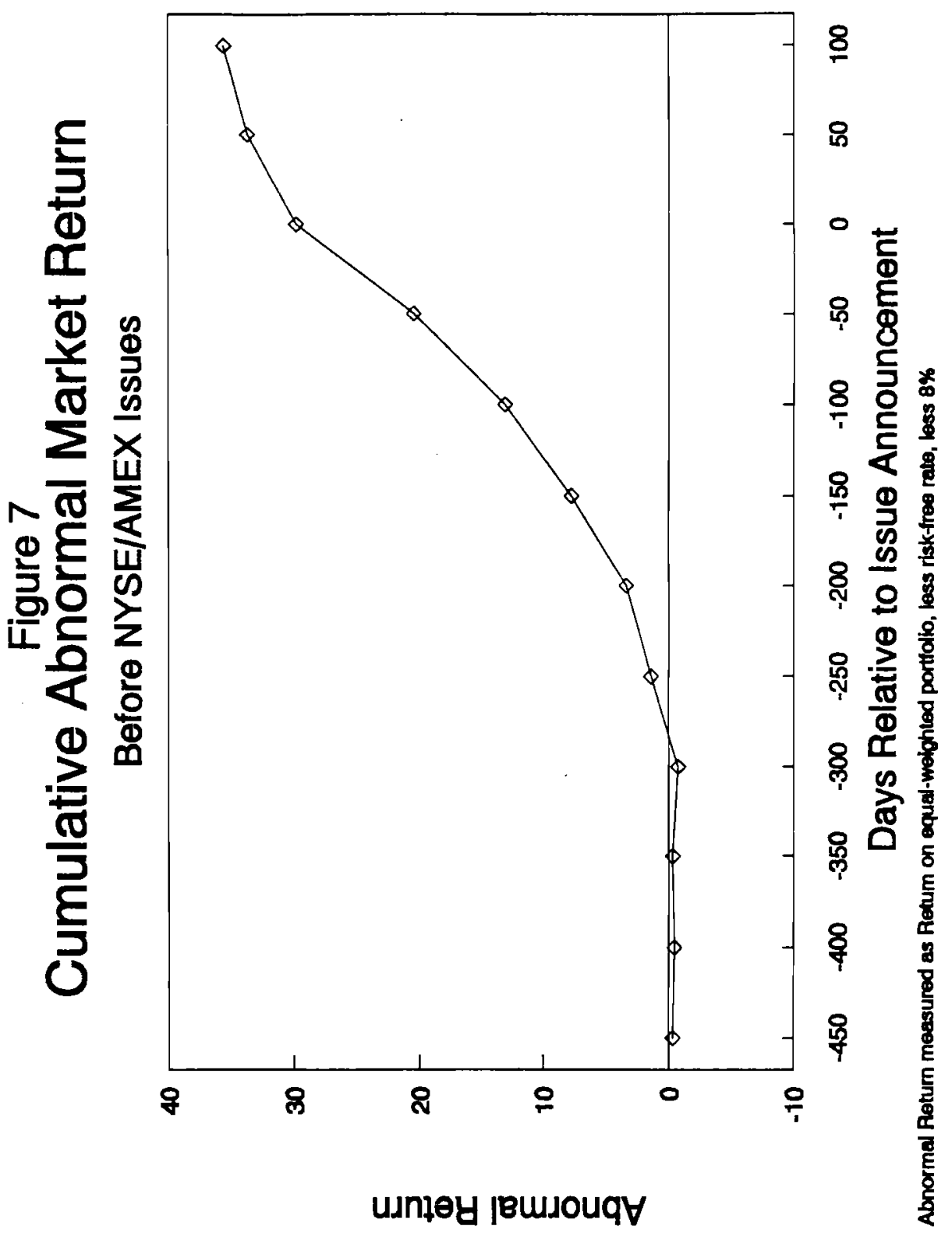


quarter was weighted by the number of issues in that quarter. Summing and dividing by the total number of issues yields the average market price path in Figure 6.

\section{Welfare Analysis}

It is natural to ask whether the magnitude of the price rise or the price drop tells us anything about the welfare costs of asymetric information. The fact that an equity issue results in a drop in the value of the firm on average equal to 308 of the capital raised (Asquith and Mullins (1986)] has led some observers to conclude that equity issues are likely to be prohibitively costly. If other forms of financing are unavailable, this suggests potentially large welfare losses. However, this need not be the case. A large price drop at issue can cccur even though welfare losses are sma11.

There are two sources of welfare loss in this model, relative to a full information setting in which all projects would be financed:

- Some projects are lost when firms go out of business while waiting for favorable market conditions to issue. In this model effective project durabilizy is increasing in $\rho$, the probability that the firm remains viable for another period.

- A project may be displaced by a new project. The probability of displacement is positively related to the project arrival rate, $q$.

The welfare loss can be measured using the ratio of projects adopted each period to project arrivals each period. Dividing equation ( 9 ) by q gives the steady state fraction of projects accepted: 


$$
\sigma=\frac{(1-p)}{1-(1-q) P p}
$$

Clearly $\sigma$ increases in $\rho$ and decreases in $q$. The total loss each period is the fraction of projects foregone times the average value of each project: $(1-\sigma) \beta_{\mathrm{H}}$. Thus if projects are fairly durable, and if the frequency with which firms have no alternative but to use equity is low, welfare losses will be minimal.

The reason that the welfare loss need not be related to the price drop at issue (or to the preceding rise) is that the price dynamics depend primarily on the manager's private information about the value of the firm next period. Algebraically, the slope of the price rise and the extent of the drop depend on the ratio $u / d$, while $\sigma$ is independent of $u / d$. By issuing shares, management effectively releases information early. This has no social. cost, although it may have a private cost to shareholders who sell immediately following the equity issue announcement. The probability of losing projects is already impounded into the stock price, and thus does not affect any of the price reactions. Thus, there is no tight link between price behavior and the social cost of asymmetric information.

\section{Concluding Remarks}

This paper presents a simple information-based model that accounts for a large number of facts about price behavior around equity issues and the timing of these issues. First, the model replicates the long price rise prior to issue. Interestingly, although the duration of the assumed information asymetry is short (the manager never has private knowledge of more than next period's valuation), the price rise can be long-lived because firms which by 
chance have many positive surprises will defer equity issues and appear to have long price run-ups. This policy also generates a realistic crosssectional distribution of pre-issue price histories. Secondly, we show that time variation in the aggregate average quality of assets generates the observed positive correlation between the volume of issues and general market returns.

It is possible that extensions of the model can explain other phenomena. For instance, a stock repurchase is the inverse of an equity issue in the sense that managers could repurchase urderpriced shares to benefit selling shareholders. We might expect that price behavior around the announcement of a stock repurchase will be the mirror image of that for an equity issue, and that repurchases will be clustered in periods following market downturns. It may also be possible to include costly debt in the model, and to analyze the debt/equity choice. Both of these areas remain for future research. 
Appendix A

\section{Sufficient Conditions for Verifying the Existence of Equilibrium}

This appendix develops more formally the maximization problem posed in the text, and proves Theorem 1, which gives a sufficient condition for a proposed issue policy to be an equilibrium policy. Also, the value function defined by (1)-(4) is solved and characterized.

Let $a_{t}=u, d$ denote the managers private knowledge about the perceived value of assets in place at time $t+1, b_{t}-\beta_{H}, \beta_{L}$ denote the presence or absence of a project, and $H_{t}$ denote all other information in the managers information set at time $t$ including the firm's history of asset value and project arrivals. Let $\sigma_{t}-\left(a_{t}, b_{t}, H_{t}\right)$ denote the current state. $E_{t}$ is the conditional expectation operator, where the expectation is conditioned on $\sigma_{t}$. The manager selects an issue policy at time $t$ as a function of his information:

$$
I_{t}\left(\sigma_{t}\right)=\left\{\begin{array}{cl}
0 ; & \text { do not issue equity this period } \\
1 ; & \text { issue equity this period }
\end{array}\right.
$$

The manager's problem is to choose $I_{t}$ each period to solve

$$
\left.J_{t}\left(\sigma_{t} ; I_{t}\right)=\max _{\left\{I_{t}\right\}}\left(1-s I_{t}\right)\left[\left(k+a_{t} b_{t}\right) A_{t} I_{t}+(1-\rho) a_{t} A_{t}+\rho E_{t}{ }_{t+1}\left(\sigma_{t+1} ; I_{t+1}\right)\right]\right\}
$$

Lemma Al: The value of following the optimal strategy is bounded above by:

$$
\mathrm{B}=\mathrm{u}+\mathrm{u} \beta_{\mathrm{H}} /(1-\rho)+\mathrm{K}[(1-\rho)+\mathrm{u} \rho] /(1-\rho)
$$

Proof: The value of the firm will obviously be greatest if projects arrive every period ( $\mathrm{q}=1$ and $\mathrm{b}=\beta_{\mathrm{H}}$ always) and investment capital is free $(s=0)$. 
Under these assumptions, it is obvious from (A1) that the optimal policy is to issue always $\left(I_{t}=1\right)$. (A1) then becomes (with $A_{t}$ normalized to 1 ):

$$
\begin{aligned}
& \mathrm{J}\left(\mathrm{d}, \beta_{\mathrm{H}}, \ldots ; \mathrm{I}\right)=\mathrm{k}+\mathrm{d} \beta_{\mathrm{H}}+(1-\rho) \mathrm{d}+\rho \mathrm{d}\left(\mathrm{pJ}\left(\mathrm{u}, \beta_{\mathrm{H}}, \ldots \mathrm{I}\right)+(1-\mathrm{p}) \mathrm{J}\left(\mathrm{d}, \beta_{\mathrm{H}}, \ldots \mathrm{I}\right)\right) \\
& \mathrm{J}\left(\mathrm{u}, \beta_{\mathrm{H}}, \ldots ; \mathrm{I}\right)-\mathrm{k}+\mathrm{u} \beta_{\mathrm{H}}+(1-\rho) \mathrm{u}+\rho \mathrm{u}\left(\mathrm{pJ}(\mathrm{u}, \beta \mathrm{H}, . ; \mathrm{I})+(1-\mathrm{p}) \mathrm{J}\left(\mathrm{d}, \beta_{\mathrm{H}}, . ; \mathrm{I}\right)\right)
\end{aligned}
$$

$\mathrm{J}\left(u, \beta_{\mathrm{H}}, \ldots ; \mathrm{I}\right)$ has the solution above.//

We now demonstrate that if it is not optimal to deviate from a proposed policy for one period, then it is not optimal to deviate for any number of periods. Let $I^{*}$ denote the proposed optimal policy, $W_{t}\left(\sigma_{t} ; I_{t} *\right)$ denote the value of following the proposed policy forever beginning at time $t$, and $w_{t}^{n}\left(\sigma_{t} ; I_{t}\right)$ equal the value of following an alternative policy $I$ for $n$ periods, and following $I *$ thereafter.

Lemma A2. If $W_{t}^{1}\left(\cdot ; I_{t}\right) \leq W_{t}\left(\cdot ; I_{t^{*}}\right)$, then $w_{t}^{n}\left(\cdot ; I_{t}\right) \leq W_{t}\left(\cdot ; I_{t}^{*}\right)$.

Proof. The proof is by induction. The base case is assumed. We need to show that if $w_{t}^{n-1}\left(. ; I_{t}\right) \leq w_{t}\left(. ; I_{t}^{*}\right)$ then $w_{t}^{n}\left(. ; I_{t}\right) \leq w_{t}\left(. ; I_{t}^{*}\right)$. By the definition of $w_{t}^{n}\left(. ; I_{t^{*}}^{*}\right)$ we have

$$
\begin{aligned}
W_{t}^{n}\left(\sigma_{t} ; I_{t}\right) & \equiv\left(1-s I_{t}\right)\left[\left(k+a_{t} b_{t}\right) I_{t} A_{t}+(1-\rho) a_{t} A_{t}+\rho E_{t} W_{t+1}^{n-1}\left(\sigma_{t+1} ; I_{t+1}\right)\right] \\
& \leq\left(1-s I_{t}\right)\left[\left(k+a_{t} b_{t}\right) I_{t} A_{t}+(1-\rho) a_{t} A_{t}+\rho E_{t} W_{t+1}\left(\sigma_{t+1} ; I * t+1\right)\right] \\
& =W_{t}^{1}\left(\sigma_{t} ; I_{t}\right) \\
& \leq W_{t}\left(\sigma_{t} ; I *_{t}\right) .
\end{aligned}
$$

Although finite deviations from the optimal policy are not optimal, it remains to show that arbitrary infinite deviations are not optimal. Suppose that there exists an. $I^{\prime}$ such that $w_{t}^{\infty}\left(\sigma_{t}, I^{\prime} t^{\prime}\right)>w_{t}\left(\sigma_{t}, I^{*}{ }_{t}\right)$ for some $\sigma$. Again let $w_{t}^{n}$ be the value of following $I^{\prime}$ for $n$ periods. Solving $w_{t}^{n}$ recursively (arguments are suppressed when obvious) gives 
$W_{t}^{n}-E_{t}\left[\left(\sum_{i=t}^{t+n-1} \rho^{i-t} \underset{j=0}{i} \underset{j=0}{i}\left(1-s I_{j}^{\prime}\right)\right]\left(\left(k+a_{i} b_{i}\right) I_{i}^{\prime} A_{i}+(1-\rho) a_{i} A_{i}\right)+\underset{j=t}{t+n-1} \prod_{j=s}\left(1-s I_{j}^{\prime}\right)\right) \rho^{n} w_{t+n}$

Since $w_{t}^{\infty}$ and $w_{t}^{n}$ are computed using the same issue policy for periods through $t+n$, we have

$$
\begin{aligned}
w_{t}^{\infty}-W_{t}^{n} & \left.=E_{t}\left[\prod_{i=t}^{t+n-1}\left(1-s I_{i}^{\prime}\right)\right] \rho^{n}\left(w_{t+n}^{\infty}-W_{t+n}\right)\right] \\
& \leq \rho^{n} B \text {, where } B \text { is defined in Lemma } A l .
\end{aligned}
$$

Since $w_{t}^{\infty}-W_{t} \leq W_{t}^{\infty}-W_{t}^{n} \leq \rho^{n} \bar{B} \rightarrow 0$ as $n \rightarrow \infty$, we have a contradiction, and have proven

Theorem 1: If a deviation from the assumed policy is not optimal for 1 pexiod, it is never optimal.

Solution to Equations (1)-(4').

If (E1)-(E4) are an equilibrium, (A1) reduces to (1) $-\left(4^{\prime}\right)$. The solution is given by

$$
\begin{aligned}
& \mathrm{V}\left(\mathrm{d}, \beta_{\mathrm{L}}\right)=\mathrm{d}\left[1+\beta_{\mathrm{H}} \rho \mathrm{qd}(1-\mathrm{p}) /(1-\rho)(1-\rho \mathrm{up}(1-\mathrm{q})]\right. \\
& \mathrm{V}\left(\mathrm{u}, \beta_{\mathrm{L}}\right)=\left[(1-\rho) \mathrm{u}+\rho \mathrm{u}(1-\mathrm{p})\left\{\mathrm{V}\left(\mathrm{d}, \beta_{\mathrm{L}}\right)+\mathrm{d} \beta_{\mathrm{H}} \mathrm{q} /(1-\rho \mathrm{up}(1-\mathrm{q}))\right\}\right] /(1-\rho \mathrm{up}) \\
& \mathrm{V}\left(\mathrm{d}, \beta_{\mathrm{H}}\right)=\mathrm{V}\left(\mathrm{d}, \beta_{\mathrm{L}}\right)+\mathrm{d} \beta_{\mathrm{H}} \\
& \mathrm{V}\left(\mathrm{u}, \beta_{\mathrm{H}}\right)=\left[(1-\rho) \mathrm{u}+\rho \mathrm{u}(1-\mathrm{p})\left\{\mathrm{V}\left(\mathrm{d}, \beta_{\mathrm{L}}\right)+\mathrm{d} \beta_{\mathrm{H}}\right\}\right] /(1-\rho \mathrm{up})
\end{aligned}
$$

Lemina $\mathrm{A3}: \mathrm{V}\left(\cdot, \beta_{\mathrm{i} i}\right)>\mathrm{V}\left(\cdot, \beta_{\mathrm{L}}\right)$.

Prop:

$$
\begin{aligned}
& \mathrm{V}\left(\mathrm{d}, \beta_{\mathrm{H}}\right)-\mathrm{V}\left(\mathrm{d}, \beta_{\mathrm{I}}\right)=\mathrm{d} \beta_{\mathrm{H}}>0 \\
& \mathrm{~V}\left(\mathrm{u}, \beta_{\mathrm{H}}\right)-\mathrm{V}\left(\mathrm{u}, \beta_{\mathrm{L}}\right)=[1-\mathrm{q} /(1-\rho \mathrm{up}(1-\mathrm{q}))] \mathrm{d} \beta_{\mathrm{H}} /(1-\rho \mathrm{up})>0 \cdot / /
\end{aligned}
$$


Appendix B

Proof of Theorem 2 .

We first compute the return for firms which have lived at least $\mathrm{n}$ periods, without conditioning upon whether they issue equity in the current period. There are $2^{n}$ possible price paths over $n$ periods. $2^{n-1}$ paths culminate in the sequence (d) (a fall in asset value), and all of these result in a terminal price of $P(0)$. Similarly, there are $2^{n-i-1}$ paths which culminate in the sequence $\{d, u, \ldots u\}$ ( $u$ repeated $i$ times), and all of these result in a terminal price of $P(i)$. There are $(\stackrel{n-i-1}{j})$ ways to arrive at this terminating sequence in which exactly $j$ up realizations occurred. (The case with $\mathrm{n}$ or more consecutive $\mathrm{u}^{\prime} \mathrm{s}$ is slightly different, and is discussed below.)

To compute returns we also must consider the purchase price n periods ago. Because of independence, the fraction purchased at the price $P(0)$ is $(1-\rho p)$, at $P(1), \rho P(1-\rho p)$, at $P(2),(\rho p)^{2}(1-\rho p)$, and so forth. (This is derived in Section 5.)

Combining terms, the total average return for stocks which reach the terminating price $P(i), i<n$, times the probability of that return, is

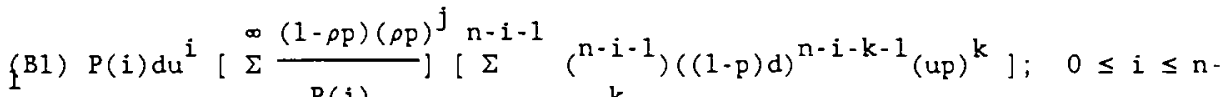
$j=0 \quad P(j) \quad k=0 \quad k$

Since the term in the last set of brackets is the binomial expansion of $[(1-p) d+u p]^{n-i-1}=1$, this can be written

$$
P(i) d u^{i}\left[\sum_{j=0}^{\infty} \frac{(1-\rho p)(\rho p)^{j}}{P(j)}\right]
$$$$
0 \leq \mathrm{i} \leq \mathrm{n}-1
$$

For sequences of consecutive $u^{\prime} s$ extending back further than $n$ periods, the purchase price must reflect exactly $n$ fewer u's than the current price. The 
combined total average return for stocks which reach the terminating price $P(j), j \geq n$, times the probability of that return, is

$$
P(i) u^{i}\left[\sum_{j=0}^{\infty} \frac{P(i+j)(1-\rho p)(\rho p)^{j}}{P(i) P(j)}\right] \quad i=n \text {. }
$$

Weighting by the appropriate probabilities, we get the following expression for the $n$-period return for all firms which survive $n$ periods:

$$
\begin{aligned}
& \sum_{i=1}^{\mathrm{n}-1} \mathrm{P}(\mathrm{i}) \mathrm{d}(1-\mathrm{p})(\mathrm{up})^{\mathrm{i}}\left(\sum_{\mathrm{k}=0}^{\infty} \frac{(1-\rho \mathrm{p})(\rho \mathrm{p})^{\mathrm{k}}}{\mathrm{P}(\mathrm{k})}\right) \\
& \quad+\mathrm{P}(\mathrm{n})(\mathrm{up})^{\mathrm{n}}{ }_{\left(\sum_{\mathrm{k}=0}^{\infty} \frac{\mathrm{P}(\mathrm{n}+\mathrm{k})(1-\rho \mathrm{p})(\rho \mathrm{p})^{\mathrm{k}}}{\mathrm{P}(\mathrm{n}) \mathrm{P}(\mathrm{k})}\right)}
\end{aligned}
$$

For future reference, (B2) is a weighted average of terms of the form (B1), with weights $\omega_{i}-(1-p) p^{i}$ for $i=0,1, \ldots, n-1$, and $\omega_{n}-p^{n}$. Thus, $\omega_{i} / \omega_{i-1}=p$ for $i=0,1, \ldots, n-1$. Note also that ( $B l a)$ and ( $B 1 b)$ are strictly increasing in i.

Now consider the return conditional upon issuing equity. Firms with a price of $P(i)$ have a project with probability $q_{i}$. Thus, to compute the return conditional upon an equity issue, we need only weight the terms in the above expression. Then (B1) can be modified:

$$
\begin{aligned}
& \left\{\sum_{i=0}^{n-1} P(i) q_{i} d(1-p)(u p)^{i}\left(\sum_{k=0}^{\infty} \frac{(1-\rho p)(\rho p)^{k}}{P(k)}\right)\right.
\end{aligned}
$$

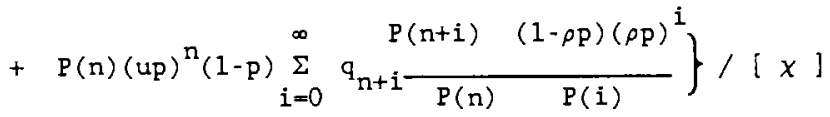

where

$$
x=\sum_{j=0}^{n-1} q_{j}(1-p) p^{j}+\sum_{j=0}^{\infty} q_{j+n}(1-\rho p) \rho^{j} p^{j+n}
$$


Equation (B3) is again a weighted average of the terms like (B1), with weights given by

$$
\Omega_{i}=\left[q_{i}(1-p) p^{i}\right] / x, \quad i-0,1, \ldots, n-1 .
$$

Since $q_{i}$ increases in $i$, the weight on the last term is greater than

$$
\Omega_{n}=\left[q_{n}(1-\rho p) p^{n}\right] / x
$$

The ratio of successive weights is $q_{i} p / q_{i-1}>$ f for $i<n$, Also $\Omega_{n} / \Omega_{n-1}>$ $\omega_{n} / \omega_{n-1}$. Thus, greater terms in (B3) have proportionately greater weights than the same terms in $(B 2)$, so $(B 3)>(B 2) \cdot / /$ 


\section{Appendix C}

In this appendix, we show that when the return on the market is timevarying, the number of issues at time $t$ is increasing in $p_{t-j}$, the fraction of firms with an asset value increase $j$ periods earlier. We do this by showing that (12) is increasing in $\mathrm{p}_{t-j}$. Similar algebra demonstrates that the market price (11) increases in $P_{t-j}$. To begin, note that for all $j$,

$$
\sum_{i=j}^{\infty}\left(1-\rho p_{t-i-1}\right) \prod_{k=1}^{i} \rho P_{t-k}-\prod_{k=1}^{j} \rho p_{t-k}=0
$$

Setting $j=0$ demonstrates that the weights in (12) sum to 1 , so that (12) is a weighted average of terms of the form $\left(1-p_{t}\right) q_{i}$.

$$
\text { Differentiating (12) with respect to } p_{t-j} \text { gives }
$$

$$
-q_{j-1} \rho \prod_{k=1}^{j-1} \rho p_{t-k}+\left[\sum_{i=j}^{\infty} q_{i}\left(1-\rho p_{t-i-1}\right) \underset{k=1}{i} \rho p_{t-k}\right] \frac{1}{p_{t-j}}
$$

This can be rewritten to give

$$
\begin{aligned}
& \frac{q_{j-1}}{p_{t-j}}\left\{\sum_{i=j}^{\infty}\left(\frac{q_{i}}{q_{j-1}}-1\right)\left(1-\rho p_{t-i-1}\right) \prod_{k=1}^{i} \rho p_{t-k}\right. \\
& \left.+\sum_{i=j}^{\infty}\left(1-\rho P_{t-i-1}\right) \prod_{k=1}^{i} \rho P_{t-k}-\prod_{k=1}^{j} \rho p_{t-k}\right\}>0
\end{aligned}
$$

From (C1), the last two terms sum to zero. Since $q$ is increasing, the first term is positive. // 


\section{References}

Asquith, Paul and David W. Mullins Jr., 1986, "Equity Issues and Offering Dilution," Journal of Financial Economics 15, pp 61-89.

Barclay and Robert Litzenberger, 1988, "Announcement Effects of New Equity Issues and the use of Intraday Price Data", Journal of Financial Economics Vo1 21, No 1 (May), pp $71-99$.

Choe, Hyuk, Ronald Masulis, and Vikram Nanda, 1989, "On the Timing of Seasoned Common Stock Issues: Theory and Evidence", Working Paper.

Drexel, Burnham, Lambert, Public Offerings of Corporate Securities (19741983)

Dybvig, Philip and Jaime Zender, 1988, "Capital Structure and Dividend Irrelevance with Asymetric Information, "Yale University working paper.

Gale, Ian, 1987, "Informational Asymmetries, Risk Attenuation and Dynamic Signalling," University of Wisconsin Dept. of Economics working paper.

John, Kose, and Joseph Williams. "Dividends, Dilution, and Taxes:

Signalling Equilibrium", Journal of Finance, Vol 40, no. 4, (September Pp. $1053-1070$.

Korajczyk, Robert, Deborah Lucas and Robert L. McDonald, 1988, "The Effect of Information Releases on the Pricing and Timing of Equity Issues: Theory and Evidence," NBER Working Paper No. 2727

Korajczyk, Robert, Deborah Lucas and Robert L. McDonald, 1989, "Understanding Stock Price Behavior Around the Time of Equity Issues", in Glenn

Hubbard, ed., Information, Capital Markets, and Investment, University of Chicago Press, forthcoming.

Masulis, Ronald and A. Korwar, 1986, "Seasoned Equity Offerings: An Empirical Investigation," Journal of Financial Economics, 15, pp $91-118$.

Mikkelson, Wayne H. and M. Megan Partch, 1986, "Valuation Effects of Security Offerings and the Issuance Process," Journal of Financial Economics 15, PP $31-60$.

Miller, Merton and Kevin Rock. "Dividend Policy Under Asymmetric Information", Journal of Finance, Vol. 40, No. 4 (September, 1985 pp. $1031-1051$.

Myers, Stewart C., and Nicholas S. Majluf, "Corporate Financing and Investment Decisions when Firms Have Information That Investors Do Not Have," Journal of Financial Economics 13, pp 187-221.

Scholes, Myron, 1972, "The Market for Securities: Substitution Versus Price Pressure and the Effects of Information on Share Prices, "Journal of Business 45 (April), PP 179-21l 
Seyhun, H. Nejat, 1986, "Insiders Profits, Costs of Trading, and Market Efficiency," Journal of Financial Economics 16, pp 189-212. 